PASSIVATION OF SEMICONDUCTOR SURFACES FOR IMPROVED

RADIATION DETECTORS: X-RAY PHOTOEMISSION ANALYSIS

A. Nelson, A. Conway, C. Reinhardt, J. Ferreira, R. Nikolic, S. Payne

December 26, 2007

Materials Research Society Fall 2007

Boston, MA, United States

November 26, 2007 through November 30, 2007 
This document was prepared as an account of work sponsored by an agency of the United States government. Neither the United States government nor Lawrence Livermore National Security, LLC, nor any of their employees makes any warranty, expressed or implied, or assumes any legal liability or responsibility for the accuracy, completeness, or usefulness of any information, apparatus, product, or process disclosed, or represents that its use would not infringe privately owned rights. Reference herein to any specific commercial product, process, or service by trade name, trademark, manufacturer, or otherwise does not necessarily constitute or imply its endorsement, recommendation, or favoring by the United States government or Lawrence Livermore National Security, LLC. The views and opinions of authors expressed herein do not necessarily state or reflect those of the United States government or Lawrence Livermore National Security, LLC, and shall not be used for advertising or product endorsement purposes. 


\title{
PASSIVATION OF SEMICONDUCTOR SURFACES FOR IMPROVED RADIATION DETECTORS: X-RAY PHOTOEMISSION ANALYSIS
}

\author{
A.J. Nelson, A.M. Conway, C.E. Reinhardt, J.L. Ferreira, R.J. Nikolic, and S.A. Payne \\ Lawrence Livermore National Laboratory, Livermore, CA, USA.
}

\begin{abstract}
Surface passivation of device-grade radiation detector materials was investigated using $\mathrm{x}$ ray photoelectron spectroscopy in combination with transport property measurements before and after various chemical treatments. Specifically $\mathrm{Br}-\mathrm{MeOH}(2 \% \mathrm{Br}), \mathrm{KOH}$ with $\mathrm{NH}_{4} \mathrm{~F} / \mathrm{H}_{2} \mathrm{O}_{2}$ and $\mathrm{NH}_{4} \mathrm{OH}$ solutions were used to etch, reduce and oxidize the surface of $\mathrm{Cd}_{(1-\mathrm{x})} \mathrm{Zn}_{\mathrm{x}} \mathrm{Te}$ semiconductor crystals. Scanning electron microscopy was used to evaluate the resultant microscopic surface morphology. Angle-resolved high-resolution photoemission measurements on the valence band electronic structure and core lines were used to evaluate the surface chemistry of the chemically treated surfaces. Metal overlayers were then deposited on these chemically treated surfaces and the I-V characteristics measured. The measurements were correlated to understand the effect of interface chemistry on the electronic structure at these interfaces with the goal of optimizing the Schottky barrier height for improved radiation detector devices.
\end{abstract}

\section{INTRODUCTION}

The development of cadmium zinc telluride $\left(\mathrm{Cd}_{(1-\mathrm{x})} \mathrm{Zn}_{\mathrm{x}} \mathrm{Te}, \mathrm{CZT}\right)$ as a nuclear radiation detector material has progressed with advances in CZT crystal growth that minimizes bulk defects and precipitates.[1,2] With this progress, our focus is now on surface properties of CZT since the interfacial chemistry has a powerful influence on the electrical stability of ohmic and Schottky contacts to CZT. The performance of CZT as a room temperature radiation detector can thus be improved with careful attention to modification of the surface chemistry. Chemical treatments of the CZT surface prior to application of electrical contacts require comprehensive characterization to elucidate advantageous changes in surface electronic structure.

Mechanical polishing followed by bromine-based etching is routinely employed for CZT surface preparation prior to device fabrication. This treatment removes the native oxide but leaves a Te-rich surface resulting in metal/CZT interface degradation and excessive leakage currents. [1-3] Alternative surface preparation methods have been proposed for surface passivation [3-6] but have not been fully characterized nor implemented for practical device fabrication.

This paper presents the results from an investigation of the surface chemistry, surface morphology and electronic structure of chemically treated $\mathrm{Cd}_{(1-x)} \mathrm{Zn}_{\mathrm{x}} \mathrm{Te}$ and correlates the results with transport properties.

\section{EXPERIMENT}

Device-grade $p-\mathrm{Cd}_{(1-\mathrm{x})} \mathrm{Zn}_{\mathrm{x}} \mathrm{Te}$ was polished and subjected to various chemical treatments. Initially a 2 min $\mathrm{Br}-\mathrm{MeOH}(2 \% \mathrm{Br})$ etch was performed and the resultant surface chemistry was 
characterized by x-ray photoelectron spectroscopy (XPS). Alternatively, following $\mathrm{Br}: \mathrm{MeOH}$ etching, the CZT was treated with $\mathrm{KOH}$ (15\% in water) for $40 \mathrm{~min}$, rinsed with DI water, then subjected to $\mathrm{NH}_{4} \mathrm{~F} / \mathrm{H}_{2} \mathrm{O}_{2}(10 \% / 10 \%$ in water) for $45 \mathrm{~min}$, rinsed again with DI water and blown dry. Concentrated $\mathrm{NH}_{4} \mathrm{OH}$ was also used to treat the oxidized CZT surface for 2 min at ambient temperature.

XPS analysis was performed on a PHI Quantum 2000 system using a focused

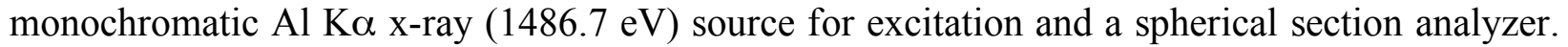
The instrument has a 16-element multichannel detection system. A 200 um diameter x-ray beam was used for analysis. The x-ray beam is incident normal to the sample and the x-ray detector is at $45^{\circ}$ away from the normal. The pass energy was $23.5 \mathrm{eV}$ giving an energy resolution of 0.3 $\mathrm{eV}$ that when combined with the $0.85 \mathrm{eV}$ full width at half maximum (FWHM) Al Ka line width gives a resolvable XPS peak width of $1.2 \mathrm{eV}$ FWHM. Deconvolution of non-resolved peaks was accomplished using Multipak 6.1A (PHI) curve fitting routines. The collected data were referenced to an energy scale with binding energies for $\mathrm{Cu} 2 \mathrm{p}_{3 / 2}$ at $932.72 \pm 0.05 \mathrm{eV}$ and $\mathrm{Au} 4 \mathrm{f}_{7 / 2}$ at $84.01 \pm 0.05 \mathrm{eV}$. Binding energies were also referenced to the $\mathrm{C}$ 1s photoelectron line arising from adventitious carbon at $284.8 \mathrm{eV}$. Low energy electrons and argon ions were used for specimen neutralization.

Diodes were fabricated by depositing platinum top contacts with guard rings and a gold backside contact. Current versus voltage measurements were performed on these diodes to determine the effect of contact interface chemistry on detector transport properties.

\section{RESULTS AND DISCUSSION}

XPS survey spectra of the etched, reduced and oxidized surfaces of $p-\mathrm{Cd}_{(1-\mathrm{x})} \mathrm{Zn}$ 的 were acquired to determine surface stoichiometry and impurity concentrations. The quantitative surface compositional analyses and elemental ratios are summarized in Table I. $\mathrm{Cd} / \mathrm{Te}$ ratio indicates that (1) $2 \% \mathrm{Br}: \mathrm{MeOH}$ etch results in a Te-rich surface, (2) $\mathrm{KOH}+\mathrm{NH}_{4} \mathrm{~F} / \mathrm{H}_{2} \mathrm{O}_{2}$ treatment results in a stoichiometric surface, and (3) $\mathrm{NH}_{4} \mathrm{OH}$ results in a Te-rich surface.

Table I. Relative XPS Surface Compositional Analysis (atomic \%) of the Chemically Treated $\mathrm{Cd}_{(1-\mathrm{x})} \mathrm{Zn}_{\mathrm{x}} \mathrm{Te}$

\begin{tabular}{|c||c|c|c|c|}
\hline Sample & Cd & Zn & Te & Cd/Te \\
\hline \hline $\mathrm{CZT}$, as received & 50.7 & 2.0 & 47.3 & 1.07 \\
\hline $\mathrm{CZT}-2 \% \mathrm{Br}: \mathrm{MeOH}$ etch & 31.6 & 2.0 & 66.4 & 0.48 \\
\hline $\begin{array}{c}\mathrm{CZT}-\mathrm{KOH}+\mathrm{NH}_{4} \mathrm{~F} / \mathrm{H}_{2} \mathrm{O}_{2} \\
\text { treatment }\end{array}$ & 50.5 & - & 49.5 & 1.02 \\
\hline $\mathrm{CZT}-\mathrm{NH}_{4} \mathrm{OH}$ treatment & 40.9 & 1.7 & 57.4 & 0.71 \\
\hline
\end{tabular}

High magnification planar view scanning electron microscopy (SEM) photomicrographs are presented in Figure 1(a) and (b), respectively, of the $\mathrm{Br}: \mathrm{MeOH}$ etched and $\mathrm{KOH}+$ $\mathrm{NH}_{4} \mathrm{~F} / \mathrm{H}_{2} \mathrm{O}_{2}$ treated CZT surfaces. The observed morphology on the surface of the Br:MeOH etched CZT has an orange peel texture. The surface morphology of the $\mathrm{KOH}+\mathrm{NH}_{4} \mathrm{~F} / \mathrm{H}_{2} \mathrm{O}_{2}$ 
treated CZT surface shows some pitting in addition to the formation of a thin surface oxide $(\approx 10$ $\mathrm{nm})$.
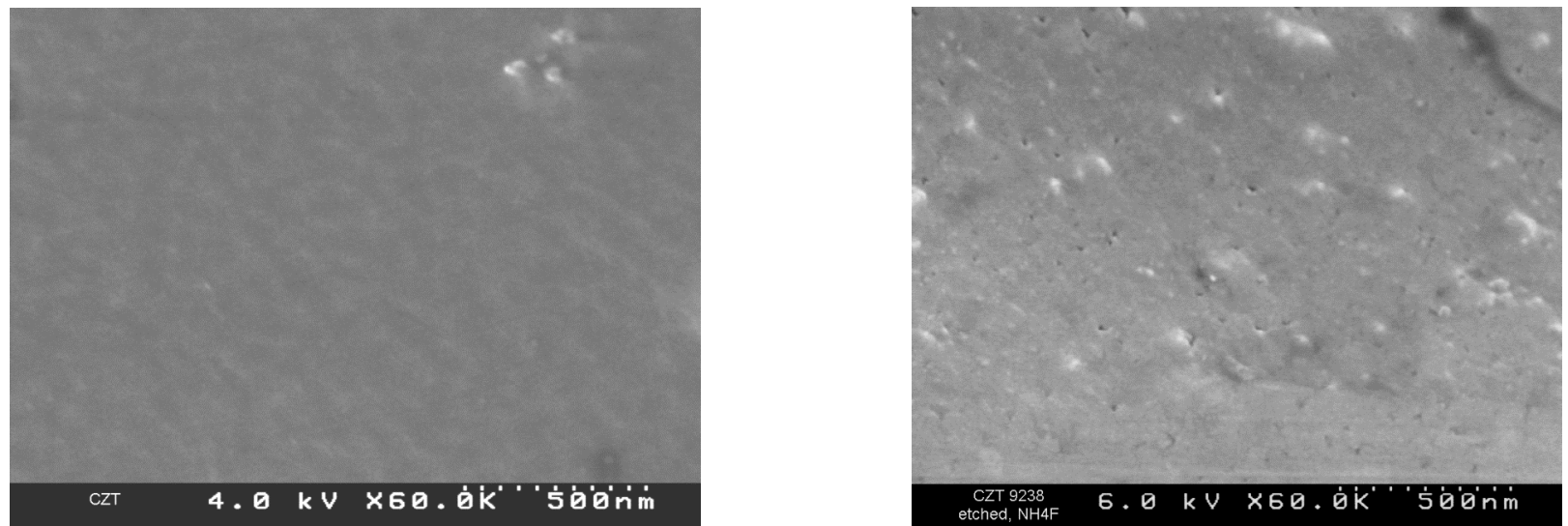

Figure 1. SEM photomicrographs of (a) $\mathrm{Br}: \mathrm{MeOH}$ etched $\mathrm{CZT}$ and (b) $\mathrm{KOH}+\mathrm{NH}_{4} \mathrm{~F} / \mathrm{H}_{2} \mathrm{O}_{2}$ treated CZT.

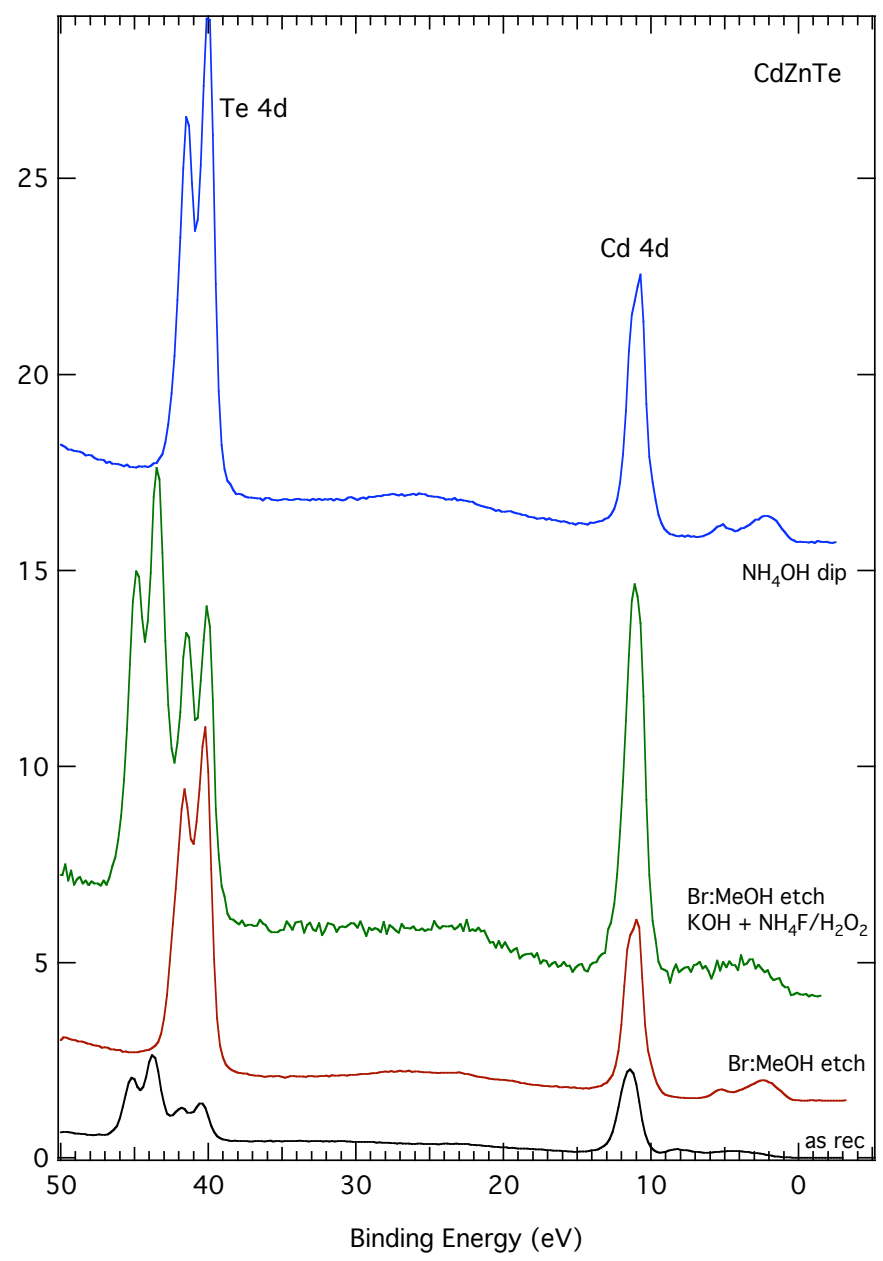

Figure 2. XPS core-level and valence band spectra for the etched and treated CZT surfaces. 
Figure 2 shows the shallow core-levels and valence band region for the as received, $\mathrm{Br}: \mathrm{MeOH}$ etched, $\mathrm{KOH}+\mathrm{NH}_{4} \mathrm{~F} / \mathrm{H}_{2} \mathrm{O}_{2}$ treated, and $\mathrm{NH}_{4} \mathrm{OH}$ etched CZT surfaces. These spectra contain the $\mathrm{Te} 4 \mathrm{~d}, \mathrm{Cd} 4 \mathrm{~d}$ and upper valence band, and provide unique information about the electronic structure and the nature of chemical bonding at the CZT surface. The evolution of the electronic structure at the surface is indicated by the transition of the valence band maximum (VBM).

In these spectra, the $\mathrm{Te} 4 \mathrm{~d}_{5 / 2,3 / 2}$ core-level has two spin-orbit pairs. The higher binding energy spin-orbit pair at $43.8 \mathrm{eV}$ and $45.0 \mathrm{eV}$ represent an oxide $\left(\mathrm{TeO}_{2} / \mathrm{CdTeO}_{3}\right)$ and the lower binding energy pair at $40.6 \mathrm{eV}$ and $41.8 \mathrm{eV}$ represents Te in CZT in agreement with literature values. [7] The Cd 4d spin-orbit pair cannot be resolved with our instrumentation, so the measured centroid of this peak is at $11.4 \mathrm{eV}$. In addition, the full width half maximum (FWHM) of the $\mathrm{Cd} 4 \mathrm{~d}$ peak indicates the presence of a surface oxide $\left(\mathrm{CdTeO}_{3}\right)$ for as received CZT. Following the $\mathrm{Br}: \mathrm{MeOH}$ etch the Te $4 \mathrm{~d}$ oxide components disappear indicating removal of the native oxide. Also, Te $4 \mathrm{~d}_{5 / 2,3 / 2}$ the spin-orbit pair and the $\mathrm{Cd} 4 \mathrm{~d}$ peak shifts $0.4 \mathrm{eV}$ to lower binding energy. In addition, the intensity of the Te $4 \mathrm{~d}$ peaks increases relative to the $\mathrm{Cd} 4 \mathrm{~d}$ intensity further supporting the presence of a Te-rich surface, possibly with the formation of Te islands. Formation of Te islands would account for the increased Te signal relative to the $\mathrm{Cd}$ signal due to the visibility of the substrate between the islands.

Following $\mathrm{KOH}+\mathrm{NH}_{4} \mathrm{~F} / \mathrm{H}_{2} \mathrm{O}_{2}$ treatment, the $\mathrm{Te} 4 \mathrm{~d}_{5 / 2,3 / 2}$ core-level spectra show two component pairs and the $\mathrm{Cd} 4 \mathrm{~d}$ core line broadens indicating oxide formation. The energy shifts observed for the $\mathrm{Te} 4 \mathrm{~d}_{5 / 2,3 / 2}$ spin-orbit components following this peroxide treatment is similar to those observed for the $\mathrm{Cd} 4 \mathrm{~d}$ core level. Also note that the relative intensity ratio of the $\mathrm{Te} 4 \mathrm{~d}$ and $\mathrm{Cd} 4 \mathrm{~d}$ has change. Recall that compositional analysis determined this to be a stoichiometric surface. Electrical contacts are deposited on this oxide surface for the following transport property measurements.

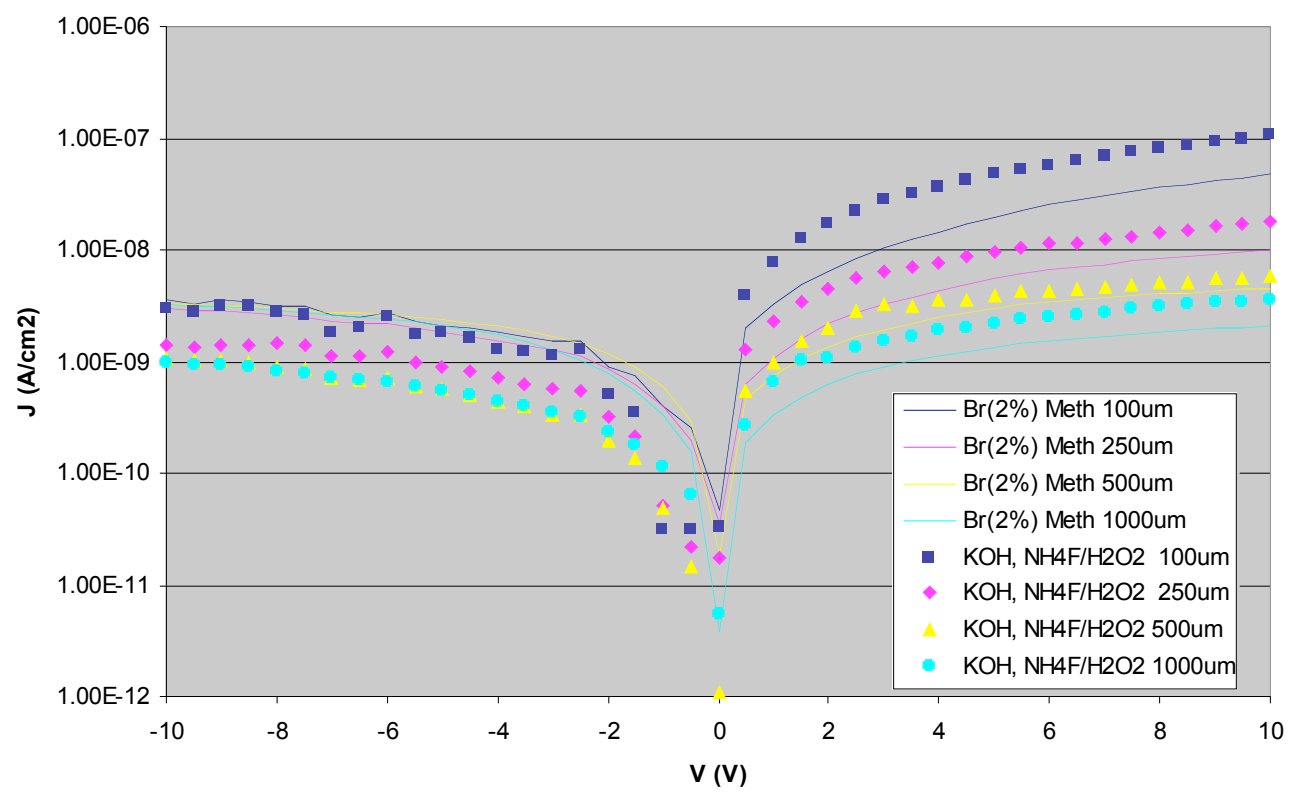

Figure 3. Characteristic I-V curves of the $\mathrm{Pt} / \mathrm{CZT} / \mathrm{Au}$ diodes as a function of surface treatment and $\mathrm{Pt}$ contact size. 
The final surface chemical treatment we explored was a $\mathrm{NH}_{4} \mathrm{OH}$ dip at ambient temperature for $2 \mathrm{~min}$. The resulting Te $4 \mathrm{~d}$ and $\mathrm{Cd} 4 \mathrm{~d}$ spectrum reveals that the oxide was removed by this treatment. Again note the change in the relative intensity ratio of the Te $4 \mathrm{~d}$ and $\mathrm{Cd} 4 \mathrm{~d}$ supporting the compositional analysis that indicated this is a Te-rich surface. This treatment could be a replacement for the standard $\mathrm{Br}: \mathrm{MeOH}$ etch for future $\mathrm{CZT}$ device fabrication.

Representative current versus voltage curves (log scale) for the diodes with guard rings are shown in Fig. 3. Rectifying behavior was achieved for the device. Note that the forward current does not scale with diode area, possibly due to a high series resistance issue. In addition, observe that there is a larger forward to reverse current ratio for $\mathrm{KOH}+\mathrm{NH}_{4} \mathrm{~F} / \mathrm{H}_{2} \mathrm{O}_{2}$ treated samples versus the $\mathrm{Br}: \mathrm{MeOH}$ etched samples. The measured resistivity $(-10 \mathrm{~V}$ effective reverse bias) is $1.6 \times 10^{10} \mathrm{ohm}-\mathrm{cm}$ for the $\mathrm{Br}: \mathrm{MeOH}$ etch versus $5.5 \times 10^{10} \mathrm{ohm}-\mathrm{cm}$ for $\mathrm{KOH}+$ $\mathrm{NH}_{4} \mathrm{~F} / \mathrm{H}_{2} \mathrm{O}_{2}$ treatment.

\section{CONCLUSIONS}

X-ray photoelectron spectroscopy has been used to determine the effects of wet chemical etching/treatment on the surface chemistry and surface electronic structure of CZT. Results show that $2 \% \mathrm{Br}: \mathrm{MeOH}$ removes the surface oxide and that the $\mathrm{KOH}+\mathrm{NH}_{4} \mathrm{~F} / \mathrm{H}_{2} \mathrm{O}_{2}$ treatment yields a well-behaved oxide surface. The $\mathrm{NH}_{4} \mathrm{OH}$ treatment resulted in an oxide free surface and may be a preferred surface preparation treatment for CZT devices. The I-V characteristics reveal that $\mathrm{KOH}+\mathrm{NH}_{4} \mathrm{~F} / \mathrm{H}_{2} \mathrm{O}_{2}$ treatment produces better blocking characteristics and lower reverse leakage currents. Future work will include treating $\mathrm{CZT}$ with $\left(\mathrm{NH}_{4}\right)_{2} \mathrm{~S}$ and $\mathrm{NH}_{4} \mathrm{OH} /$ thiourea solutions and measuring I-V/C-V characteristics.

\section{ACKNOWLEDGMENTS}

This work performed under the auspices of the U.S. Department of Energy by Lawrence Livermore National Laboratory under Contract DE-AC52-07NA27344.

\section{REFERENCES}

1. T.E. Schlesinger, J.E. Toney, H. Yoon, E.Y. Lee, B.A. Brunett, L. Franks, and R.B. James, Materials Sci. Eng. 32, 103 (2001).

2. T. Takahashi and S. Watanabe, IEEE Trans. Nucl. Sci. 48(4), 950 (2001).

3. K.-T. Chen, D. T. Shi, H. Chen, B. Granderson, M. A. George, W. E. Collins, and A. Burger, J. Vac. Sci. Technol. A15(3), 850 (1997).

4. S. Wenbin,W. Kunshu, M. Jiahua, T. Jianyong, Z. Qi and Q. Yongbiao, Semicond. Sci. Technol. 20,343 (2005).

5. V. G. Ivanitska, P. Moravec, J. Franc, Z. F. Tomashik, P. I. Feychuk, V. M. Tomashik, L. P. Shcherbak, K. Masek, and P. Hoschl, J. Electron. Mater. 36(8), 1021 (2007).

6. L. Qiang and J. Wanqi, Surface states and passivation of p-Cd0.9Zn0.1Te crystal, Nucl. Instrum. Methods A 562(1), 468 (2006).

7. P. John, T. Miller, T.C. Hsieh, A.P. Shapiro, A.L. Wachs, and T.-C. Chiang, Phys. Rev. B34, 6704 (1986). 